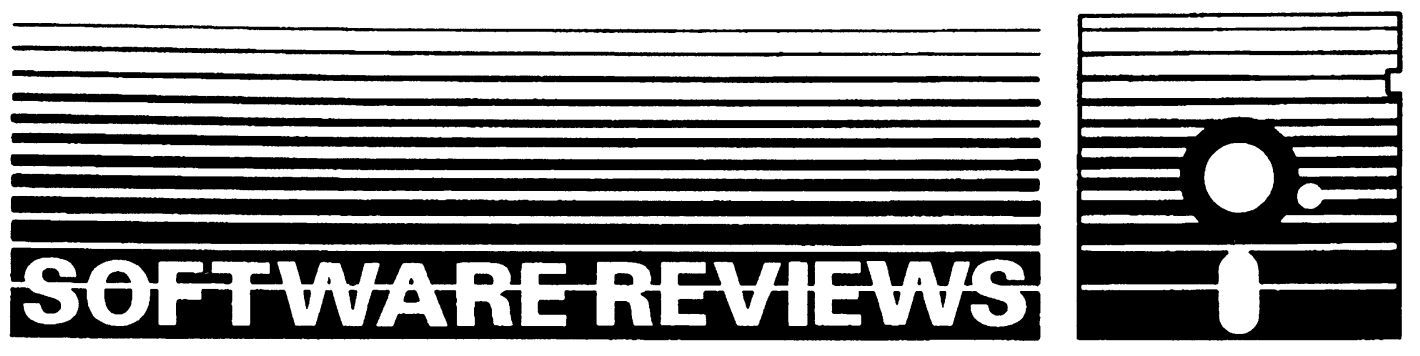

\title{
PcGIVE PROFESSIONAL 8: A REVIEW
}

\author{
ALVARO ESCRIBANO \\ Departamento de Estadística y Econometria, Universidad Carlos III de Madrid, c/Madrid 126, Getafe 28903, Spain
}

\section{INTRODUCTION}

PcGive Professional 8 is an interactive, menu-driven program for estimation, hypothesis testing, and evaluation of economic models in the context of dynamic systems. It consists of PcGive 8, for single-equation modelling, and a fully revised version of PcFiml for systems of equations. With PcGive 8 it is easy and natural to implement the econometric methodology advocated by David Hendry and others; see Cook and Hendry (1994) for a recent exposition. Interesting examples of applications and descriptions of the methodology underlying PcGive include Davidson et al. (1978), Hendry and Richard (1983), Ericsson et al. (1990), Hendry and Ericsson (1991), and the PcGive manual. Applications of the econometric methodology underlying PcFiml 8 include Chong and Hendry (1986), Engle and Granger (1987), Johansen (1988), Lutkepohl (1991), Johansen and Juselius (1992), Boswijk (1992), and Hendry and Mizon (1993). The PcFiml manual gives a general introduction and includes very interesting tutorials. This review concentrates on the main characteristics of PcGive Professional 8 and on changes over previous versions; see Ericsson and Lyss (1991) and Teräsvirta (1988) for reviews of PcGive 6.01 and 5.01, respectively.

\section{OVERALL PHILOSOPHY AND OBJECTIVE}

PcGive 8 is a multipurpose program especially designed to model autoregressive distributed lag (ADL) models using the general-to-specific strategy. It is especially useful for applied economists studying macroeconomic time-series data. The program and the manual provide an intensive evaluation of the estimated models and residuals. This helps applied econometricians avoiding the temptation to interpret and report empirical results based on models which have not been adequately tested. The almost automatic battery of misspecification tests, although it is very convenient, has to be carefully interpreted, because many of the test statistics are not 
independent, and some critical values might not be correct when variables are non stationary. For good recommendations on how to interpret the results of test statistics and $P$ values, see Mackinnon(1992) and the PcGive and PcFiml manuals. The program is exciting to use live in the classroom, since it is quick in numerical computation and flexible and clear in the way the results and graphics are presented on the screen. Sessions can be logged (commands recorded in a file) and rerun on later occasions. This is especially useful in live presentations. Empirical results are sent automatically to a 'results window' where you can enter comments or delete unnecessary results. The possibility of editing the 'results window' should be very useful for instructors preparing empirical questions for exams or homework and for applied researchers who wish to add comments or suggestions during the modelling process.

PcFiml 8 is designed for modelling linear systems of equations with time-series data. The system of equations can include behavioural relationships as well as identities, and so it can be used to estimate and evaluate full macroeconometric models. The interface is the same as the one in PcGive 8 and therefore all comments previously made about editing the results and 'live' teaching facilities apply to PcFiml as well.

The main problem one has to face when modelling dynamic systems of equations, such as vector autoregressions (VAR) or vector autoregressions with moving average terms (VARMA), is information overload, because of the large number of parameters and the possible cancellations (common factors) between the AR and the MA polynomials. To overcome this difficulty, PcFiml is based on the VAR class of models, with possibly some exogenous variables. For selecting the order of the VAR, it extends the set of misspecification tests of PcGive to systems of equations and combines them with correlation analysis and with graphical evaluations of residuals. The tutorials are very useful in explaining the details of how to implement this procedure. The overall methodological philosophy of econometric modelling with PcFiml is similar to that of PcGive.

The main advantages of PcGive 8, PcFiml 8, and their corresponding manuals over competing packages are that they are easy and flexible to use, they include advanced and basic econometric techniques, they automatically encourage misspecification and specification testing of estimated economic models, and they explicitly suggest a progressive and constructive empirical modelling strategy. Berk (1987) argued that the primary concern of microcomputer statistical and econometric software is to encourage good statistical practice, and PcGive Professional definitely follows that path. It could have an enormous positive influence among applied economists and statisticians, and it should motivate interesting applied econometric research.

\section{GLOBAL EVALUATION}

Berk (1987) suggested a long list of properties that a statistical package should have. The following list indicates how many of these PcGive Professional 8 possesses:

\section{Documentation}

- The manuals show readily what is available and how to do it: YES

- Help screens depend on the context: YES

- Examples convey a flavour of the package: YES

- Appropriate statistical advice is often given: YES

- The manual gives a feeling for the level of the intended audience: YES 


\section{Language}

- The package is easy to learn and easy to use: YES

- The package allows variables to be named mnemonically and to be referenced by name: YES

- The options can be run by menu screens and command mode: NO

- The sequence of options selected from menus can be retained and rerun: PcGive NO, PcFiml YES

- The package has an internal editor: YES

- There is a command-driven mode for data transformations: YES

- When the user makes errors the program reacts with dignity (one is not thrown out into the operating system): YES

Data entry, editing and listing

- Data may be entered directly or imported from an outside file: YES

- ASCII files can be imported and exported: YES

- Data editing is accomplished with the screen showing the data in the context of neighbouring variables: YES

- There is an internal missing data code that propagates automatically when the data are transformed: YES

- It is possible to generate random data: YES

- It is known how much data can be handled: YES

- There is a good facility for listing data: YES

\section{Data manipulation}

- The package has variety of facilities for manipulating the data: YES

- Allows specification through algebraic formulas: YES

- Has descriptive statistics: YES

\section{Graphics}

- Possible to superimpose several plots: YES

- Has high-resolution graphics: YES

- Has high-resolution graphics output available for a variety of printers: YES

\section{Procedures}

- The package has a variety of estimation procedures: YES

- The package has residual analysis: YES

- Influence diagnostics are available: NO

- The program allows user specification of what test to use: YES

\section{Output}

- It is possible to direct the output to the, screen, the printer, or a file: YES

- Output is properly formatted and labelled: YES

- Test statistics are accompanied by their corresponding tail probabilities: YES 


\section{Customizing}

- It is possible to add procedures in the language the package is written in: NO

- The source code is available to the user: NO

- A macro language is available for custom applications: NO

- The package has a matrix language: NO

\section{Environment}

- The programs are written in a compiled language (such as C or Fortran): YES

- Written for MS/PC DOS operating system: YES

- Allows execution of operating-system commands from within the package: YES

- The package has reduced systems requirements in terms of hard disk, numeric coprocessor, ram memory: YES

\section{Support}

- Free telephone consultation: NO

- Authors react constructively to reports of bugs and deficiencies: YES

- Owners of the program get a discount on upgrades to the new version: YES

\section{Overview}

- Is the package appropriate for the needs of some group of users? YES

- Does it fill the needs of an econometrics course? YES

- Is the package authored by an econometrician? YES

\section{SYSTEM REQUIREMENTS, PRICES, AND DISTRIBUTION}

\subsection{System Requirements}

PcGive Professional 8 (PcGive and PcFiml) requires an IBM PC or compatible (PC, XT, AT, 80386 , or higher) running DOS 3.3 or higher. They will also run from a DOS window under Windows. The PC needs at least $460 \mathrm{~KB}$ of free conventional memory and $1.2 \mathrm{MB}$ of free extended memory for 386 versions, plus $4.2 \mathrm{MB}$ on a hard disk. A mathematics co-processor is strongly recommended, although not required, as is a mouse. Hercules, CGA, MCGA, EGA, VGA, and super-VGA video cards are all supported.

\subsection{Prices}

Prices (in pounds sterling, VAT is extra) are as follows. Prices for educational users are shown first, followed by prices for commercial users in parentheses.

(1) Additional copies of the documentation: $£ 25$ per volume

(2) Single-copy price: $£ 200$ ( $£ 300)$

(3) Discounted upgrades for users of PcGive 7 (only for 6 months): $£ 135$ (£200)

(4) Limited site licence:

- Normal price: $£ 200$ ( $£ 300)$ base price $+£ 100(£ 150)$ per extra CPU

- Discounted upgrades for users of PcGive 7 (only for 6 months): $£ 135$ ( $£ 200$ ) base price $+£ 77.50(£ 100)$ per extra CPU 
(5) Unlimited site licence (includes four copies of each of the two manuals, additional copies can be purchased at $33 \%$ off):

- Normal price: $£ 1200$ ( $£ 2400$ )

- Discounted upgrades for users of PcGive 7 (only for 6 months): $£ 600$ ( $£ 1600$ )

\subsection{Authors}

Jurgen A. Doornik and David F. Hendry

Institute of Economics and Statistics

University of Oxford

Oxford OX1 3UL, UK

\subsection{Distributors}

For North America:

Fred Osborne

TCI Software Research

1190 Foster Road

Las Cruces

New Mexico 88001, USA

Tel. +1 505-5224600

Fax +1 505-5220116

For outside North America:

Richard Pilkington

International Thomson Publishing

168-173 High Holborn

London, WC1V 7AA

United Kingdom

Tel. +44-71-4971422

Fax +44-71-4971426

\section{DOCUMENTATION}

\section{Part A: Manuals}

The printed documentation consists of two manuals, one for PcGive and one for PcFiml. The PcGive manual has four parts:

- Part I: five chapters with a review of the econometrics of PcGive and with some comments on econometrics teaching and practical problems.

- Part II: seven chapters on tutorials. These are clearly explained and are highly recommended to get a quick idea about how to efficiently use the program

- Part III: two chapters documenting the structure and functioning of the program.

- Part IV: appendices about printing graphs, etc.

The PcFiml manual has six parts:

- Part I: two chapters on installation and a general introduction to PcFiml, plus advice about how to use the manual. 
- Part II: seven chapters on tutorials. These tutorials are very important to understand and learn about the large number of estimation procedures and specification tests of systems of equations. For example, the tutorials explain in detail how to estimate, by Johansen's (1988) procedure, the cointegrating rank and how to impose and estimate different cointegrating restrictions. Some other advances features like recursive FIML, constrained FIML, dynamic simulation, impulse response analysis, and forecasting with systems of equations are also explained in detail.

- Part III: six chapters which explain the econometrics contained in PcFiml. It is worth reading these to understand and correctly interpret the outputs of the program. The contents of these chapters are almost a textbook on the modern approach to the econometrics of simultaneousequations models.

- Part IV: explains the statistics computed and reported by PcFiml.

- Part V: complements the general information of the PcGive manual. It applies only to PcFiml and not to PcGive. It includes batch files, configuration files, and command line options.

- Part VI: contains some appendices about the DOS extender to access memory above the 640KB limit, about PcFiml error messages, and about the artificial data set used in the tutorial sessions.

\section{Part B: On-line Help}

- The Help options depend on the context.

- The help system explains both the program usage and the econometrics.

\section{ESTIMATION, GRAPHICS, AND TESTS: A SUMMARY}

In the following Tables I and II we reproduce the main list of procedures for estimation, graphics, and testing available in PcGive and PcFiml.

Table I. Estimation procedures

PcGive PcFiml

Ordinary least squares, recursive least squares

Instrumental variables, recursive instrumental variables

$R$ th order autoregressive least squares (RALS)

Programmable options include:

nonlinear least squares (NLS), recursive NLS (e.g. recursive RALS), maximum likelihood (only sums of individual likelihoods, including, for example, ARCH, binary logit, tobit, etc.)

Engle-Granger two-step
Multivariate least squares, recursive multivariate least squares

Two-stage least squares, limited information instrumental variables

Three-stage least squares, full information instrumental variables, full information maximum likelihood (FIML), recursive FIML

FIML with nonlinear parameter constraints (CFIML), recursive CFIML 
Table II. Evaluation procedures

PcGive

Graphic analysis of residuals, outcomes and forecast, including

Recursive graphs including graphs of residual sums of squares, coefficients, residuals and three types of constancy Chow tests

One-step forecasts, standard errors and tests

Tests for ARCH, various forms of heteroscedasticity, serial correlation, functional form, etc.

Common factor tests and encompassing tests (nonnested tests)

Tests for linear restrictions and omitted variables

Cointegration analysis, including computation of long run, significance of lags and graphic overview of lag weights, PcGive unit roots tests
PcFiml

Graphic analysis for each equation in the system, up to 16 graphs at a time

Recursive graphs including graphs of residual and three sum of squares, likelihood, single-equation and system Chow tests, recursive test over identifying restrictions

Dynamic simulation and impules response analysis

Dynamic forecasts and $h$-step forecasts with standard errors

Single-equation diagnosis: as in PcGive

System tests: vector portmanteau, vector autocorrelation, vector normality, vector functional form

Tests for linear and nonlinear restrictions

Dynamic analysis of lag-one multipliers, long-run matrix, long-run covariance, long-run multipliers, static long run, standard errors of static long run, eigenvalues of long-run matrix and eigenvalues of companion matrix

Cointegration graphics: cointegration vectors, actual and fitted, components, recursive eigenvalues, etc.

Tests for cointegration restrictions on loadings and eigenvectors, including a new switching algorithm allowing any (even nonlinear) restrictions

\section{FUTURE DEVELOPMENTS}

PcGive Professional 8 is a highly recommended, interactive, easy-to-use, menu-driven program for econometric analysis of single equations and systems of equations. However, I do have a few suggestions for future versions. A more sophisticated editor with greater word-processing capabilities should be incorporated to be able to generate final econometric reports. It would be useful to be able to save (retrieve) intermediate calculations and manipulate matrices to be able to check some results or to compute alternative estimators. In PcFiml, a matrix language and other multivariate statistical procedures, such as factor analysis, principal components, etc., would be useful.

The authors mention a list of very interesting immediate projects: A new version of Stamp (Structural time series analyser, modeller and predictor) in cooperation with A. C. Harvey, S. J. Koopman, and N. Shephard, PcGive Professional for Microsoft Windows, and a new version of PcNaive.

I am sure PcGive Professional and the new developments will have an enormous positive 
influence among applied economists and statisticians and that they will motivate interesting econometric topics for research.

\section{ACKNOWLEDGEMENTS}

Helpful comments and suggestions from Jurgen Doornik, Neil Ericsson, David Hendry, and James MacKinnon are gratefully acknowledged.

\section{REFERENCES}

Berk, K. N. (1987), 'Effective microcomputer statistical software', The American Statistician, August, 41, No.3.

Boswijk, H. P. (1992), Cointegration, Identification and Exogeneity, No. 37 of Timbergen Institute Research Series, Thesis Publishers, Amsterdam.

Cook, S. and D. F. Hendry (1994), 'The theory of reduction in econometrics', Idealization in Economics, Poznan Studies in the Philosophy of Science and the Humanities, Vol. 38, Rodolpi, Atlanta, GA, pp. 71-100.

Chong, Y. Y. and D. F. Hendry (1986), 'Econometric evaluation of linear macroeconomic models', Review of Economic Studies, 53, 671-90.

Davidson, J. E. H., D. F. Hendry, F. Srba and S. Yeo (1978), 'Econometric modelling of the aggregate time-series relationship between consumers expenditure and income in the United Kingdom', Economic Journal, 88, 352, 661-692.

Engle, R, F. and C. W. J. Granger (1987), 'Cointegration and error correction: representation, estimation and testing, Econometrica, 50, 987-1007.

Ericsson, N. R., J. Campos and H. Tran (1990), 'PC-GIVE and David Hendry's econometric methodology'. Revista de Econometría, X, No. 1, 7-117.

Ericsson, N. R. and H. Lyss (1991), 'An update to PC-GIVE: version 6.01', Journal of Applied Econometrics, 6, 321-5.

Hendry, D. F. and G. E. Mizon (1993), 'Evaluating dynamic econometric models by encompassing the VAR', in P. C. B. Phillips (ed.), Models, Methods and Applications of Econometrics, Basil Blackwell, Oxford, pp. 272-300.

Hendry, D. F. and N. R. Ericsson (1991), 'An econometric analysis of UK money demand', in Monetary Trends in the United States and the United Kingdom by Milton Friedman and Anna J. Schwartz, American Economic Review, 81, 8-38.

Hendry, D. F. and J. F. Richard (1983), 'The econometric analysis of economic time series', International Statistical Review, 51, 2, 111-63 (with discussion).

Johansen, S. (1988), 'Statistical analysis of cointegration vectors', Journal of Economic Dynamics and Control, 12, 231-54.

Johansen, S. and K. Juselius (1992), 'Testing structural hypotheses in a multivariate cointegration analysis of the PPP and the UIP for UK', Journal of Econometrics, 53, 211-44.

Luitkepohl, H. (1991), Introduction to Multiple Time Series Analysis, Springer-Verlag, New York.

MacKinnon, J. G. (1992), 'Model specification test and artificial regressions', Journal of Economic Literature, XXX, 12-146.

Teräsvirta, T. (1988), 'A review of PC-GIVE: a statistical package for econometric modelling', Journal of Applied Econometrics, 3, 333-40. 